\title{
Context Sensitive Solutions: A Case Study of Jamestown Corridor Improvements in Virginia
}

\author{
Dale M. Stith ${ }^{1}$ and Eunsu Lee ${ }^{2}$ \\ 1. Hampton Roads Transportation Planning Organization, Chesapeake VA 23320, USA \\ 2. School of Business, New Jersey City University, Jersey City NJ 07311, USA
}

\begin{abstract}
This paper deals with a case study of a context-sensitive solution of the Jamestown Corridor, located along James City County and the City of Williamsburg in Virginia. The corridor is an important passageway to many tourist attractions in the Historic Triangle of Hampton Roads. During the improvement process, the project should minimize the congestions impacts, maximize convenience, safety and reliability of the surrounding transportation systems, minimize social impact to the local community and address long-term capacity issues. Through the project, the agencies involved learned that projects near any of the historic resources must be context-sensitive and should include all stakeholders early and often to make sure that a comprehensive schedule was developed. They also learned that time should be considered for review and input from key regional stakeholders for a variety of issues.
\end{abstract}

Key words: Context-sensitive solution, public involvement, Jamestown Corridor Improvements.

\section{Introduction}

The Jamestown Corridor, located in James City County and the City of Williamsburg, is an important passageway to many tourist attractions in the Historic Triangle of Hampton Roads (Jamestown, Colonial Williamsburg and Yorktown). In 2007, the 400th commemoration of the settling of Jamestown was held: In preparation for this event, vital transportation improvements were needed to this corridor, including improvements to Virginia State Route 199 and the relocation of Virginia State Road 359 [1].

Virginia State Route 199 (VA-199), also known as Humelsine Parkway, is a primary limited-access state highway that runs 14.13 miles from Interstate 64 (I-64) and State Road 646 in Lightfoot to State Road 641 near the City of Williamsburg. VA-199 forms a western loop of Williamsburg and provides access to several highways that serve historic attractions in the region. The section of VA-199 south of Williamsburg, from

Corresponding author: EunSu Lee, Ph.D., assistant professor, research fields: operations management, transportation and logistics, transportation modeling, intermodal transportation and transportation planning. E-mail: elee3@njcu.edu.
VA-5 to I-64, was completed in 1977. The original facility was built as mostly 4-lane with two separate 2-lane sections (built on a 4-lane right-of-way). The 4-lane northwestern extension of VA-199 was opened in August 1999, completing the Williamsburg beltway (Fig. 1).

VA-199 has a few intersections along its route, including the congested intersection with Jamestown Road (SR-31) in the City of Williamsburg, which was in need of improved traffic flow. Virginia State Route 359 (SR-359), located in front of the Visitors Center at the Jamestown Settlement, is a short connector between Jamestown Road (SR-31) and the Colonial Parkway, and it provides access from the Jamestown Settlement and Visitors Center to the original settlement and archeology site of Historic Jamestown on Jamestown Island. The original SR-359 cut through the Jamestown museum parking lot and presented safety concerns, especially in regards to bicycle and pedestrian traffic.

The Historic Triangle includes the historic and tourist attractions of Jamestown, Colonial Williamsburg and Yorktown, which are connected by 


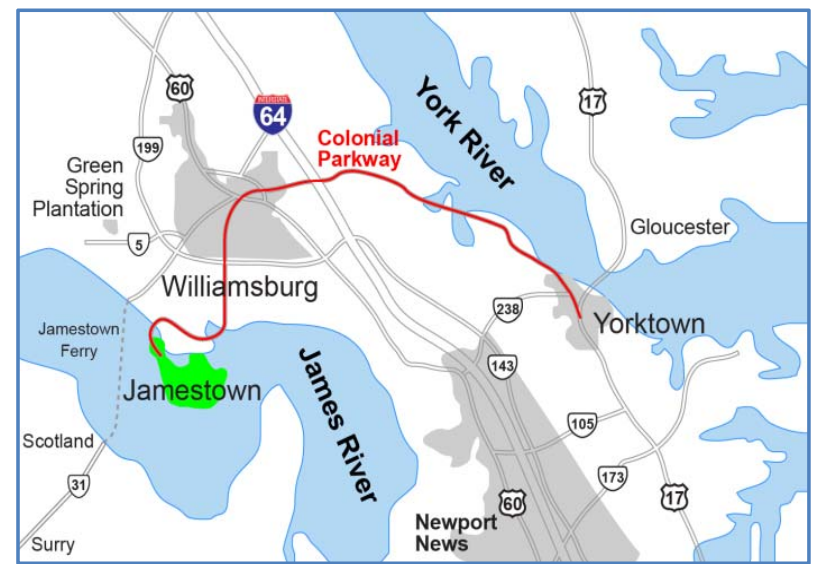

Fig. 1 Route of Colonial Parkway.

the Colonial Parkway. These sites are of major historical significance to Virginia and the nation.

Jamestown was the first permanent English settlement in the New World (established in 1607). It consists of two major areas today: (1) the Jamestown Settlement, which is a living-history museum that includes replica ships from the original settlers and re-creations of a native-American village and colonial fort; (2) the Historic Jamestown, located on Jamestown Island, which is the original settlement and is part of the National Park Service. This Historic Jamestown area is an archaeological site with ongoing archaeological projects.

In 1699, the capital of Virginia was moved from Jamestown to Williamsburg. Williamsburg was established in 1693 and was considered as a prominent place until the Virginia capital was moved to a more secure location in Richmond in 1780. Today, Colonial Williamsburg is a large living-museum of early American life and is a very popular tourist destination. It has dozens of restored and re-created buildings with many re-enactors portraying colonial life.

Yorktown is the site where General Cornwallis surrendered to George Washington in 1781 and was the last land battle of the American Revolution. Many of the Revolutionary War battlefields have been preserved in Yorktown and the area is a popular tourist destination.

The Colonial Parkway, also part of the National Park Service, connects these three historic sites along a
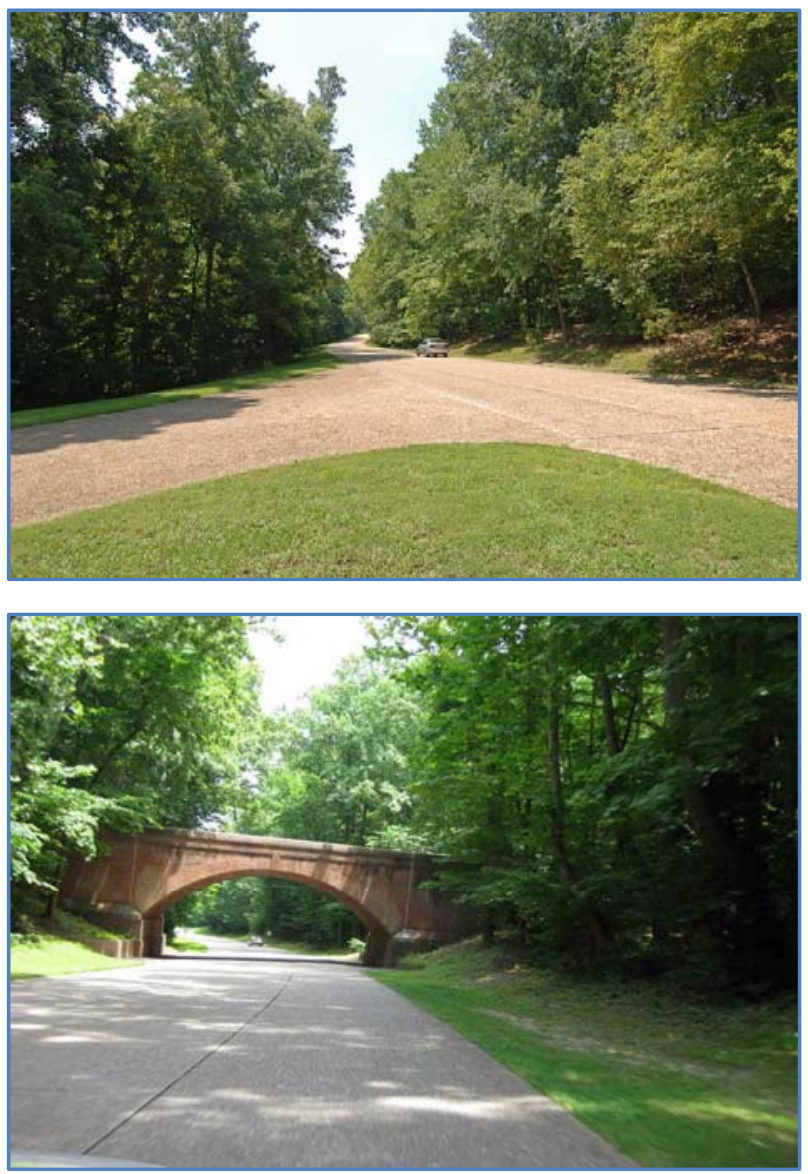

Fig. 2 Colonial Parkway.

Source: VDOT (Virginia Department of Transportation).

scenic and rustic roadway (Fig. 2). The parkway runs from Jamestown to Yorktown, passing through Colonial Williamsburg along the way. In keeping with its historic setting, the parkway is carefully shielded from views of commercial development. No commercial vehicles are allowed to use the parkway, although commuter traffic has picked up in the past decade as the surrounding areas of James City and York Counties along with the City of Williamsburg continue to develop.

\section{Problems to Be Solved}

The daily traffic on VA-199 was approximately 30,000 vehicles per day [1]. According to the VDOT (Virginia Department of Transportation), volumes on the facility were forecasted to increase to 45,400 vehicles per day by the year 2018 [1]. As mentioned previously, the 400th anniversary 
commemoration of the settling of Jamestown in 2007 was anticipated to bring thousands of additional tourists to the area. Since this corridor is considered an important passageway to historic tourist attractions which have significant economic benefits not only to the Historic Triangle but also to the entire Hampton Roads region and even the Commonwealth of Virginia, improvements to this corridor would ease traffic concerns during the commemoration, as well as address long-term capacity issues in the future [1].

The problems to be solved on this corridor were to enhance accessibility between the three anchors of the Historic Triangle, improve intersection operational and capacity issues, address pedestrian safety concerns and address future capacity issues while maintaining the historic context of the area [1].

The recommendations in the scope of work for the Jamestown Corridor Improvements project included the following objectives [1]:

(1) minimize the congestions impacts of the anticipated events on the regional highway system;

(2) maximize convenience, safety and reliability of the surrounding transportation system for a relaxed and pleasurable visitor experience;

(3) minimize impacts to the local community by physically separating visitor traffic from local traffic as much as possible [2];

(4) address long-term capacity issues along this corridor.

\section{Stakeholders}

Some of the major planning groups for this project included:

- Jamestown 2007 Steering Committee, APVA (Association for the Preservation of Virginia);

- Colonial National Historical Park;

- Jamestown-Yorktown Foundation;

- Jamestown 400th Commemoration Commission;

- Virginia Educational Institutions;

- Virginia Cultural Network;

- Virginia African American Forum;
- VDOT;

- Virginia Department of Rail and Public Transportation;

- Jamestown 2007 Stamp and Cachet Group;

- Local and State Agencies and Businesses;

- Department of Interior;

- Civic organizations;

- Heritage and cultural groups and citizens;

- Communities across the state.

\section{Context-Sensitive Solution Approaches}

As far as the project development process, VDOT is committed to being flexible, incorporating innovative designs and providing CSS (Context Sensitive Solutions) to address transportation challenges. As such, VDOT promotes the involvement of all relevant stakeholders and citizens in the development process to reflect a community's value and preserve the scenic, historic and environmental resources, while providing enhanced mobility without compromising safety [3]. VDOT's CSS policy includes the following key characteristics [3]:

- open, honest, early and continuous communication with all stakeholders;

- a multidisciplinary project development team including the public stakeholders;

- a consensus on clearly defined project purpose, need and scope before proceeding to detailed development;

- a project development process tailored to meet project specific circumstances;

- a commitment to process from top agency officials and local leaders;

- a public involvement process tailored to project specifics;

- an understanding of geography, community and valued resources before planning and engineering design is started;

- a full range of communication tools used to clearly visualize the project;

- a commitment to fully examine all modes of travel 
and intermodal solutions;

- a balance of safety, mobility, community and environmental goals.

\subsection{Design Flexibility and Application of Design Criteria}

For the Jamestown Corridor Improvements project, designers set out from the start to produce a quality transportation project that fits physically and visually within the cultural and historic surroundings. The corridor also met the needs of users and neighboring communities all within the compressed project schedule in order to be properly prepared for the 400th commemoration of Jamestown - an event, which had the potential to increase tourism and expand economic development in the area [1].

In order to prepare for the 400th commemoration, the Jamestown Corridor Improvements were needed to help facilitate the anticipated increase in travel demand (due to both the Jamestown celebration, as well as forecast increases from anticipated population and employment increases). Additionally, because these transportation improvements were needed in a compressed time schedule, VDOT signed a comprehensive agreement with Jamestown 2007 Corridor Constructors, LLC in December 2002, using the provisions of the Public Private Transportation Act of 1995 to complete these improvements [4].

VA-199 is an integral component of the Jamestown Corridor. This facility functions as a bypass route around downtown Williamsburg facilitating the separation of local and visitor traffic. The daily traffic on SR-199 was approximately 30,000 vehicles per day [1]. SR-359 is a local street connecting SR-31 and the Jamestown Settlement with the Colonial Parkway, and it is a critical link for auto and bus access to the original settlement on Jamestown Island.

The Jamestown Corridor Improvements project consists of five construction segments $[1,4,5]$.

\subsubsection{Segment I}

Segment I widens VA-199 to a 4-lane section from
Route 60 to the Colonial Parkway overpass and includes the intersection with Mounts Bay Road and the crossing of Tutters Creek. The widened facility will have 12-ft lanes, an 8 -ft paved right shoulder and a 3 -ft paved left shoulder, with a $40-\mathrm{ft}$ wide median (Fig. 3).

\subsubsection{Segment II}

Segment II widens VA-199 to a 4-lane section from the Henry Street South intersection to Brookwood Drive. The widened facility will also have 12-ft lanes, an 8-ft paved right shoulder and a $3-\mathrm{ft}$ paved left shoulder, with a 40-ft wide median. Major construction efforts will include a parallel 2-lane 837-ft bridge over College Creek and its wetlands (Fig. 3).

\subsubsection{Segment III}

Segment III improves turn lanes at the VA-199 and Jamestown Road (VA-31) intersection. Existing turn lanes will be lengthened, and a new turn lane is provided for eastbound VA-199 traffic turning onto southbound VA-31 toward Jamestown. A new turn lane for westbound VA-199 traffic turning north on VA-31 will be added and a third right turn lane will be added for VA-31 north traffic turning east on VA-199. Maintaining access to all businesses will be a priority for work in this segment.

\subsubsection{Segment IV}

Segment IV relocates existing SR-359 to reduce potential vehicular/pedestrian conflicts and to facilitate improved access to the Jamestown facilities (Fig. 4). A

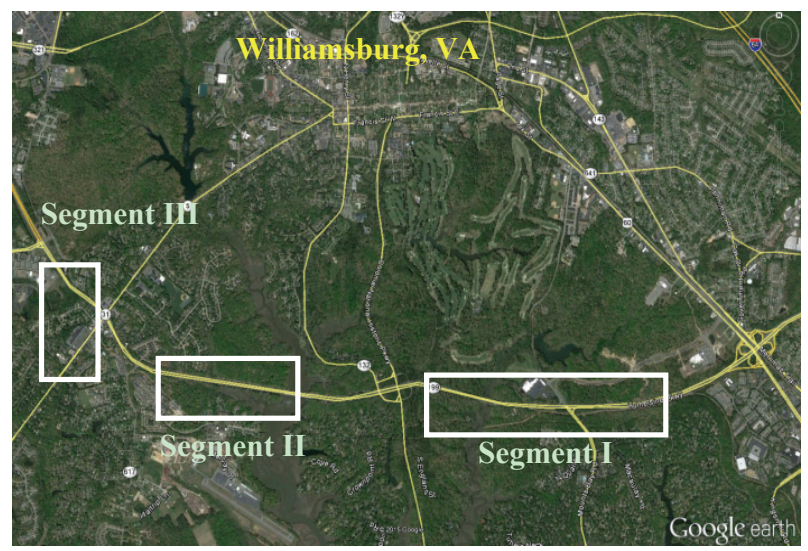

Fig. 3 Segments to improve (Segments I, II and III). Source: VDOT and Google Earth. 


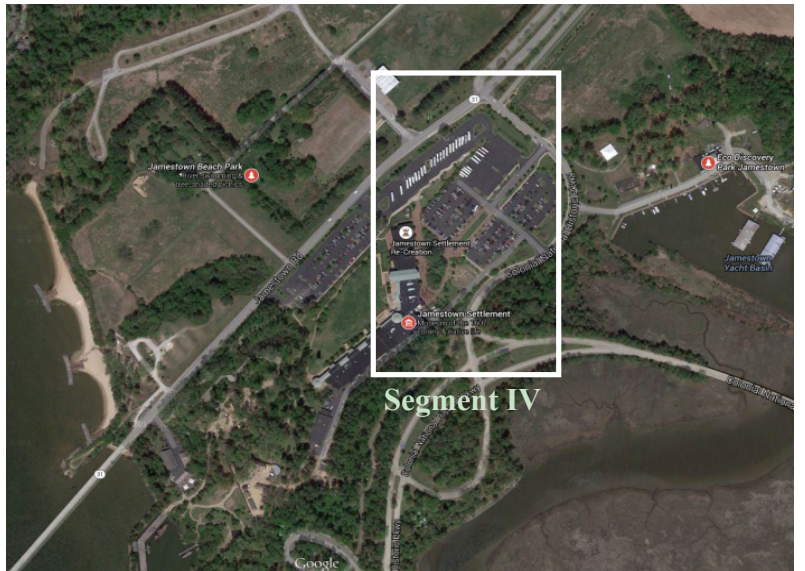

Fig. 4 Segments to improve (Segment IV).

Source: VDOT and Google Map.

new 2-lane facility connecting Jamestown Road (VA-31) with the Colonial Parkway will be constructed.

\subsubsection{Segment V}

Segment V provides enhanced landscaping and beautification at various locations along the Route 199 and Route 31 corridors.

\subsection{Stakeholder Involvement: Challenges and Concerns}

Soils surrounding College Creek and the tributary basin areas presented challenges during construction. The project team worked together to develop a design for reinforced fills that would support the traffic loading while also minimizing any long-term settlement below subgrade, which would result in a failing roadway section or create future maintenance issues [4].

According to the Jamestown Corridor Improvements Quarterly Report, community stakeholders (local elected leaders and residents) expressed a desire for pedestrian signals at the intersection of VA-199 and VA-31. However, additional funding could not be identified and, therefore, the pedestrian signals could not be incorporated, decreasing the effectiveness of the intersection improvements [1].

Historical and cultural resources were another significant issue. The Department of Interior was an integral partner on the project team due to the sensitivity of work on the property of the National Park Service [4]. Project development included time consideration for the necessary surveys and phased clearances of impacted properties along the corridor [4]. All sites were cleared for construction and then monitored throughout as required by the permitting [4]. The project team maintained great relationships with the stakeholders from the historical and cultural resources and received high praise from the National Park Service for their attention to the Park Service concerns, as well as the quality of performance [4].

Another contentious issue during project development included the relocation of SR-359. Certain stakeholders from the Jamestown 2007 Steering Committee, the Association for the Preservation of Virginia, and the National Park Service opposed the proposed VDOT design to re-route SR-359, stating that it will confuse visitors going to Jamestown Island [6]. However, officials at the Jamestown Settlement (the living-history museum) supported the design, stating that the re-routing is needed because of safety concerns with the current road alignment that cuts between a parking lot and the museum [6]. Specifically, the VDOT design called for the current SR-359 to be closed and a new roadway would connect farther north up Jamestown Road (VA-31), loop behind the expanded museum parking lot and wind back up to Colonial Parkway [6]. Opposing stakeholders suggested a plan to keep the current roadway open but allow for another road to lead visitors to new entrances to the expanded parking lot [6]. The project team adjusted plan designs, revising the horizontal and vertical alignments of the relocated facility to provide enhanced access to the expanded parking lot at the Jamestown Settlement museum and utilized the existing facility as an additional access point to the relocated SR-359 [7].

\section{Lessons Learned}

The Jamestown Corridor Improvements were completed ahead of time. Utilizing the PPTA process, 
VDOT was able to procure a design-build contract to complete the expansion of VA-199 from two to four lanes with a divided median for approximately 3 miles, improve the interchange at VA-199/VA-31, and relocate SR-359 to address pedestrian and accessibility concerns [8]. This project required exact planning and phased design and construction in order to achieve the aggressive schedule, as well as support uninterrupted traffic on VA-199 [9].

Through the years, VDOT has learned that projects near any of the historic resources in the Historic Triangle, and the Colonial Parkway must be context sensitive. Lessons learned that made this project a success include partnering with all stakeholders early and often to make sure that a comprehensive schedule was developed and included time consideration for review and input from key regional stakeholders for issues regarding permitting, necessary design approvals, utility relocations, etc. [9]. The project team also held "mandatory" weekly meetings, challenging stakeholders to come prepared and to address items, such as design submittals, revision or approval status, deficiency identification/correction and documentation, status of right-of-way acquisition negotiation and status of utility relocation [9]. This partnering approach gave members a sense of "ownership" where each individual believed success was the only option and attendees were inspired to come prepared to support the progress of the work and performance of the project team [9]. Having key stakeholders involved from the beginning and with a strong sense of "ownership" were integral components in the success of this project.

Philip A Shucet, the Interim General Manager of Hampton Road Transit stated that "this project is a good example of how design-build can work, and work well" [4]. VDOT Chief Engineer Malcolm Kerley added that the project team "completed each phase of the project well ahead of schedule" and the "proactive collaboration with VDOT and communications with the local governments and the citizens led to strong community support for the work" [4].

James City County Administrator Sanford Wanner stated that "clearly, the success of the Jamestown Corridor Improvements was a result of the team's dedication and commitment to quality" [4]. In regards to finishing well ahead of schedule, Williamsburg City Manager Jackson Tuttle added, "for finishing well ahead of schedule, saving over 3/4 million in taxpayer dollars and achieving an exceptional safety record, you should be very proud. I particularly want to thank you for your creative and thorough work on behalf of the City of Williamsburg to resolve the many difficult issues surrounding the reconstruction of the Route 199/Jamestown Road intersection located within the city limits" [4].

\section{References}

[1] VDOT (Virginia Department of Transportation). 2007. "VTrans2025 Multimodal Impact Statement (MMIS): Jamestown 2007 Anniversary Celebration." University of Virginia. Accessed March 12, 2014. http://www.virginia.edu/crmes/multimodal/downloads/Jam estown\%202007.doc.

[2] Vanasse Hangen Brustlin, Inc. 2004. Master Plan for Jamestown Beach Campground Appendix G: Traffic Impact Analysis. Richmond: Vanasse Hangen Brustlin, Inc.

[3] VDOT. 2006. Context-Sensitive Solutions Memorandum. Richmond: VDOT.

[4] VDOT. 2012. Attachment 4.0.1.1, Letter of Submittal Checklist and Contents. Richmond: VDOT.

[5] Kozel, S. 2005. "Jamestown VA Corridor Improvements Near Completion.” VDOT. Accessed March 12, 2014. http://newsgroups.derkeiler.com/Archive/Misc/misc.transp ort.road/2005-09/msg01962.html.

[6] Whitson, B. 2001. "Jamestown Road Debate Remains Tense." Newport News: Daily Press. Accessed March 12, 2014. http://articles.dailypress.com/2001-07-21/news/0107 210044_1_jamestown-settlement-colonial-parkway-parkin g-lot.

[7] Stringfield, E. 2014. Interviewee. Transportation Planning and Land Use. Richmond: VDOT.

[8] Curtis Contracting, Inc. 2012. I-64/Route 15 (Zion Crossroads) Interchange Improvement. West Point: Curtis Contracting, Inc.

[9] VDOT. 2012. "Attachment 4.0.1.1. Virginia Capital Trail-Varina Phase. Letter of Submittal Checklist and 
Contents." VDOT. Accessed March 12, 2014. http://www.virginiadot.org/business/resources/APD_Docs
/Price_Proposal/86280_-_LOS_and_Price_Proposal_-_Cu rtis.pdf. 